\title{
Posvenção com pais enlutados: uma estratégia de cuidado no contexto do suicídio
}

\author{
Posvención con padres en duelo: una estrategia de cuidado en el contexto del suicidio
}

\author{
Posvention with bereaved parents: a care strategy in the context of suicide
}

\author{
Luana Dondé Tochetto \\ Universidade de Caxias do Sul (UCS), Caxias do Sul - RS/Brasil \\ ORCID: 0000-0001-8852-2185 \\ E-mail: luanadtpsico@gmail.com
}

Raquel Furtado Conte

Universidade de Caxias do Sul (UCS), Caxias do Sul - RS/Brasil ORCID: 0000-0002-2378-8772

E-mail: rfconte@ucs.br

\begin{abstract}
Resumo
O presente trabalho tem por objetivo salientar a importância do cuidado com pais que perderam filhos jovens por morte voluntária, ou seja, suicídio. Devido ao tema da morte por suicídio ainda ser considerada um tabu e estigma, esses pais muitas vezes encontram-se num luto não reconhecido ou não franqueado, não recebendo os devidos cuidados que favoreça a elaboração desse luto. O trabalho pretendeu realizar um levantamento bibliográfico de estratégias de cuidados para pais enlutados no contexto do suicídio. Para isso, foi realizado uma pesquisa bibliográfica de cunho qualitativa e de abordagem descritiva e exploratória. Para a coleta de dados da literatura foi utilizado como instrumento uma ficha bibliográfica construída pelas autoras. Após a leitura exploratória, seletiva e interpretativa das obras e artigos encontrados partiu-se para a análise dos dados, a partir de uma síntese integradora. Os resultados apontaram que a posvenção é uma intervenção eficaz para auxiliar o processo de luto desses pais, a fim de que consigam elaborar os sentimentos e pensamentos relativos ao evento traumático ocorrido com seus filhos. Nesse sentido, serviços e políticas públicas podem ser importantes aliados para a realização dessa intervenção com essa população.
\end{abstract}

Palavras-chaves: Suicídio; Luto por suicídio; Pais enlutados; Posvenção; Sobreviventes por suicídio.

\section{Resumen}

El presente trabajo tiene como objetivo enfatizar la importancia del cuidado de los padres que han perdido hijos pequeños por muerte voluntaria, es decir, suicidio. Debido a que el tema de la muerte por suicidio sigue siendo considerado un tabú y un estigma, estos padres muchas veces se encuentran en un duelo no reconocido o desprovisto de derechos, sin recibir los debidos cuidados que favorezcan la elaboración de ese duelo. El trabajo pretendió realizar un levantamiento bibliográfico de las estrategias de atención a los padres en duelo en el contexto del suicidio. Para ello, se realizó una investigación bibliográfica cualitativa con enfoque descriptivo y exploratorio. Para la recolección de datos bibliográficos se utilizó como instrumento un formulario bibliográfico construido por los autores. Luego de la lectura exploratoria, selectiva e interpretativa de los trabajos y artículos encontrados, el análisis de los datos partió de una síntesis integradora. Los resultados mostraron que la postvención es una intervención eficaz para ayudar al proceso de duelo de estos padres, para que puedan desarrollar sentimientos y pensamientos relacionados con el evento traumático ocurrido con sus hijos. En este sentido, los servicios y las políticas públicas pueden ser importantes aliados para realizar esta intervención con esta población.

Palabras clave: Suicidio; Duelo por suicidio; Padres en duelo; posvención; Supervivientes de suicídio.

\footnotetext{
Abstract

The present work aims to emphasize the importance of caring for parents who have lost young children by voluntary death, that is, suicide. Due to the theme of death by suicide still being considered a taboo and stigma, these parents often find themselves in an unrecognized or unfranchised mourning, not receiving the proper care that favors the elaboration of this mourning. The work intended to carry out a bibliographic survey of care strategies for bereaved parents in the context of suicide. For this, qualitative bibliographic research with a descriptive and exploratory approach was
} 
carried out. For the collection of literature data, a bibliographic form built by the authors was used as an instrument. After the exploratory, selective and interpretative reading of the works and articles found, the data analysis started from an integrative synthesis. The results showed that postvention is an effective intervention to help the grieving process of these parents, so that they can develop feelings and thoughts related to the traumatic event that occurred with their children. In this sense, services and public policies can be important allies to carry out this intervention with this population.

Keywords: Suicide; Mourning suicide; Bereaved parents; Posvention; Suicide survivors.

\section{Introdução}

Segundo os dados divulgados pela Organização Mundial de Saúde (OMS) em 2016

(https://www.paho.org/pt/topicos/suicidio) o suicídio é um grave problema de saúde pública e é a segunda causa de morte entre jovens entre 15 à 25 anos. Segundo Botega (2015), ele representa uma tragédia no âmbito pessoal e um sério problema de saúde pública. $\mathrm{O}$ aumento desenfreado das taxas de jovens que tiram suas vidas é alarmante. Estima-se que para cada suicídio, de cinco a seis pessoas sejam diretamente afetadas, o que faz, somente no Brasil, com que mais de 70 mil pessoas, anualmente, sejam consideradas sobreviventes do suicídio.

No Brasil houve um aumento progressivo da mortalidade por suicídio ao longo das últimas décadas, sendo que a taxa de suicídio no Brasil aumentou $7 \%$ nos últimos dez anos, passando de 5,7 para 6,1 mortes a cada 100.000 habitantes. Levando em conta, ainda, que cada suicídio afeta gravemente a vida de seis a dez pessoas, podemos afirmar que este é um fenômeno que impacta consideravelmente a vida humana.

O luto por si só é um processo delicado e angustiante. De acordo com Franco (2010), o luto não é apenas uma experiência difícil aos sobreviventes, mas um momento de crise em que ocorre um desequilíbrio entre a quantidade de ajustamento necessário de uma única vez e os recursos disponíveis para lidar com ele. Dessa forma, são necessários ao indivíduo enlutado tempo e recursos para sua recuperação. No que tange ao processo do luto, Parkes (2009) salienta que ele implica em uma mudança significativa na vida, subjetiva e individual, cujo impacto mexe com todas as dimensões humanas: emocional, cognitiva, física, religiosa, familiar, social e cultural. Para o autor, o sujeito enlutado está implicado numa tarefa de transição e reorganização psicossocial com alto investimento emocional, frente a questões que provocam mudanças profundas em relação ao sentido da vida.

Após um suicídio ocorre o processo de luto dos familiares, sendo que o luto dos pais que perdem filhos por suicídio passa a ser ainda mais doloroso (Casellato, 2002). A autora aponta para a contramão da morte de um filho, contrariando o ciclo vital. Além disso, a perda inesperada e violenta está associada com o luto traumático, o qual é vivenciado com intenso sofrimento. Justamente por ser um tema associado a preconceitos e tabus, o suicídio não é visto como uma maneira aceitável de morrer. Casellato (2002) e Botega (2015) nos convocam a refletir sobre a tarefa silenciosa e isolada dos sobreviventes por suicídio, uma vez que os sentimentos dolorosos podem ser negados, assim como a causa da morte pode ser escondida.

O luto que não pode ser expresso ou suportado pela sociedade é também denominado de Luto não reconhecido. O impacto de estar enlutado dessa maneira é tão significativo que ter um vínculo com alguém que tirou sua vida passa a ser um dos principais riscos de futuro suicídio. Chama-se quem vive esse processo de luto "sobrevivente", seja amigo, colega ou familiar; porém, o impacto de ser sobrevivente tem sido mais extensamente tratado no contexto das famílias enlutadas por suicídio (Tavares, 2013).

Em suicidiologia, o termo sobrevivente de um suicídio é utilizado para designar as pessoas que de alguma maneira foram atingidas por essa experiência, que se obrigaram a passar 
por algum tipo de mudança drástica e de reorganização em suas vidas. Embora os membros familiares sejam os mais atingidos por esse fato, a noção de sobrevivente também abarca as pessoas que têm sua vida modificada de uma maneira negativa por este gesto (Botega, 2015). O autor refere algumas situações de suicídio, nos quais várias pessoas são afetadas pela perda de um indivíduo, como a escola, a família, dentre outros espaços nos quais o suicida deixa memórias e lastros.

Ao falar sobre o luto, Fukumitsu e Kóvacs (2015) citam uma interferência em todas as dimensões humanas do indivíduo, sendo elas: física, emocional, comportamental, espiritual, cognitiva e social. Além de possuir diversas e individuais formas de expressar a dor, como alterações de humor, de sono, raiva, isolamento social, choro fácil, necessidade de falar sobre a pessoa perdida. (Casellato, 2015).

A morte por suicídio pode gerar sentimentos como vergonha, as pessoas tendem a julgar e estigmatizar o enlutado. Existe uma dificuldade muito grande na sociedade em aceitar e acolher esses pais enlutados por suicídio. Esses enlutados acabam silenciando suas dores, gerando muitos segredos e perguntas sem respostas (Kovács, 2003).

No caso de luto de pais pela perda de um filho por suicídio, inverte a lógica natural do ciclo de vida, por isso, Bromberg (1998) afiram que não podemos comparar a outro tipo de luto. Pais enlutados por suicídio são considerados vulneráveis devido à vivência traumática da perda de um filho e pelo luto não reconhecido, composto por sentimentos como desorientação, desconforto e constrangimento, gerando fatores de risco para um processo de luto complicado. Para o pesquisador, esse tipo de luto vai contra o natural do ciclo vital, como por exemplo a perda de um filho jovem e, por isso, apresenta maior risco para que a pessoa desenvolva complicações, entre essas complicações podese citar a ideação suicida.

O estigma associado a morte por suicídio é citado como um dos fatores que dificultam para os enlutados lidarem com sua perda e com os possíveis julgamentos sociais, por se tratar de forma pouco aceitável de morrer/morte (Botega, 2015; Kovács, 2003). Além da dificuldade em identificar e encontrar serviços que ofereçam atividades para auxiliar os enlutados, outra dificuldade apontada pelos pesquisadores se refere ao ato de retomar suas vidas normalmente apesar do ocorrido. Além de existir esse afastamento natural do próprio sobrevivente, Casellato (2015) expõe a dificuldade que a sociedade tem em amparar e acolher o enlutado por suicídio, que está relacionada com a própria dificuldade em compreender e significar tal ato.

Parkes (2009) salienta que as mortes mais traumáticas são as súbitas, inesperadas e prematuras, tendo a maior probabilidade de originar problemas do que as que tenham sido antecipadas ou para as quais houve preparo. Esse luto pode ser complicado, assim como os lutos que incluem testemunhar violência ou mutilação, mortes com um culpado (incluindo assassinato e suicídio) e mortes que não permitem recuperação de um corpo intacto. Esses sobreviventes experienciam intensa ansiedade, hipervigilância e reação de espanto, bem como medo e desamparo, quando lembram da perda. As mortes traumáticas podem trazer lutos complicados manifestado por sintomas físicos e mentais que fortemente propiciam a negação e a repressão da dor pela perda. Os sobreviventes encontram-se incapazes, pressionados pela sociedade a se controlar, não manifestar suas tristezas, e, por consequência, se sentem solitários, frágeis e depressivos.

Em 2014 foi lançada a cartilha Suicídio: informado para prevenir pela Associação Brasileira de Psiquiatria. Na cartilha o luto do suicídio é visto como um processo de adaptação à perda da morte por suicídio pelo qual a família, amigos e outras pessoas próximas vivenciam. Portanto os enlutados que passam por esse processo são denominados como "sobreviventes do suicídio". Quando ocorre uma morte por suicídio, uma parte da sociedade sofre seus efeitos. Alguns dados apontam que cerca de 60 pessoas são afetadas a cada morte. $\mathrm{Na}$ cartilha existe recomendações para que o paciente e a família recebam acompanhamento 
para impedir e prevenir novas tentativas, além de salientarem a importância de pessoas em processo de luto serem auxiliadas.

A partir da constatação de que os pais enlutados por suicídio têm dificuldade para encontrar apoio social, foi criado o conceito de posvenção. Esse conceito foi desenvolvido por Shneidman (1973) e refere-se ao cuidado oferecido aos sobreviventes enlutados por suicídio, sejam eles: familiares, amigos, colegas e todos aqueles que foram afetados direta ou indiretamente por uma morte por suicídio. É considerado uma ferramenta de cuidado com saúde mental indispensável nesses casos. As ações de posvenção podem ser consideradas preventivas para as gerações futuras, visto que, além de promoverem um espaço de cuidado aos enlutados, podem ter a função de promover o acesso à informação, auxiliar na construção de diálogos sobre o tema e, consequentemente, contribuir para a diminuição do tabu em relação ao suicídio. Com o objetivo de realizar um levantamento bibliográfico de estratégias de cuidados para pais enlutados no contexto do suicídio, foram elencados os artigos em banco de dados atualizados, a fim de aprofundar o tema.

\section{Método}

Esta pesquisa bibliográfica tem um delineamento descritivo e exploratório. Para a viabilização da leitura dos temas, as autoras incialmente realizaram uma revisão da literatura, a fim de introduzir o tema e propor a inserção de dados atuais, a partir da coleta de dados atuais. Portanto, livros e artigos conhecidos previamente pelas autoras também compuseram o arcabouço teórico.

A busca de dados foi realizada nas seguintes bases de dados eletrônicos: Google acadêmico e SciELO (Scientific Electronic Library Online - http://www.scielo.org/), no período de 2016 a 2021. Dentre os materiais apresentados no google acadêmico, foram explorados apenas os artigos que se encontravam em revistas científicas. Os descritores utilizados foram: suicídio; sobreviventes; luto por suicídio, luto não reconhecido, posvenção. Os critérios de inclusão dos artigos foram: artigos completos em língua portuguesa e publicados no período entre os anos de 2016 e 2021, para que a produção contemplasse dados baseados na atualidade. Como critério de exclusão adotouse: os materiais que não permitiam acesso gratuito ao texto completo, considerando a necessidade de leitura integral para manter a fidedignidade na produção de conhecimento; as produções realizadas por áreas de conhecimento não focadas em saúde mental, a fim de manter a coerência e alinhamento entre os dados coletados e os objetivos do trabalho; e as obras que não concatenassem os descritores entre si, uma vez que cada descritor relacionase a um vasto tema de pesquisa e o objeto de estudo deste trabalho é a relação entre eles.

Como procedimentos foi realizada a leitura seletiva, exploratória e analítica dos dados encontrados, selecionando aqueles que estavam de acordo com objetivos do estudo. Os artigos foram registrados numa Ficha Bibliográfica, elaborada pelas autoras, para posterior categorização de temas para a análise e integração. O referencial de análise utilizado foi a síntese integradora (Salvador, 1986). De acordo com o autor, ela é resultante da análise e reflexão dos documentos selecionados. Implica na compreensão das atividades relacionadas à apreensão do problema, investigação rigorosa, visualização de soluções e síntese. A síntese integradora é o momento de ligação com o material de estudo, para leitura, anotações, indagações e explorações, cuja finalidade consiste na reflexão e na proposição de soluções.

De acordo com as orientações de Salvador (1986) e Lima e Mioto (2007), para a realização da síntese integradora dos artigos encontrados, foi utilizado o critério do parâmetro temático, uma vez que esse norteia a seleção do material a partir de temas correlatos. A partir da leitura exploratória que consiste em verificar se as informações selecionadas interessam ao estudo, partiu-se para a leitura seletiva, reflexiva e interpretativa. Na leitura seletiva foi identificado o material que interessava ao estudo, de acordo com o objetivo 
do estudo. Na leitura reflexiva foi realizado o ordenamento e a sumarização das informações contidas. Por último, na leitura interpretativa, foi realizada a associação e comparação de ideias entre os artigos encontrados, a partir de uma atitude que demanda a liberdade de pensar e a capacidade de criar.

\section{Resultados}

A partir dos critérios de inclusão e exclusão elencados acima, sete artigos foram elencados para a discussão. Com base nos procedimentos de leitura realizados, os artigos foram agrupados por temáticas pertinentes ao objetivo desse estudo. Dessa forma, nas Tabelas abaixo encontram-se os artigos selecionados e já reunidos por temas.

Percebe-se um pequeno avanço de pesquisas na área nos últimos anos, porém ainda se trata de uma temática pouco estudada. Entre os sete artigos selecionados, dois deles descreviam acerca do luto de pais sobreviventes por perda de filhos por suicídio e a atuação do psicólogo, três discutiam sobre a posvenção, três discutiram as especificidades da perda por suicídio e das repercussões dessa na família. A tabela ilustra os artigos que foram analisados:

Tabela 1

Luto de pais Sobreviventes por perda de filhos por suicídio e atuação do psicólogo

\begin{tabular}{ccc}
\hline Título & Ano & Autor \\
\hline $\begin{array}{c}\text { Luto materno no suicidio: a impotência e o } \\
\text { desamparo frente as (im)possibilidades }\end{array}$ & 2020 & Serra, A. P. E. \& Freitas, J. L. \\
\hline $\begin{array}{c}\text { Situação de Suicídio: Atuação do Psicólogo } \\
\text { junto a pais enlutados }\end{array}$ & 2021 & Feijoo, A. M. L. C \\
\hline
\end{tabular}

Nota. Tabela elaborada pelas autoras

Tabela 2

Posvenção

\begin{tabular}{ccc} 
Título & Ano & Autor \\
\hline $\begin{array}{c}\text { Estratégias de prevenção e posvenção do } \\
\text { suicídio: Estudo com profissionais de um } \\
\text { Centro de Atenção Psicossocial. }\end{array}$ & 2017 & Müller, S. A., Pereira, G. \& Zanon, R. B \\
\hline $\begin{array}{c}\text { Suicídio: a importância de novos estudos de } \\
\text { posvenção no Brasil. }\end{array}$ & 2019 & Ruckert, M. L. T; Frizzo, F. P. \& Rigoli, \\
& M. M. \\
\hline $\begin{array}{c}\text { Grupo de Apoio aos Enlutados pelo } \\
\text { Suicídio: uma experiência de posvenção e } \\
\text { suporte social. }\end{array}$ & 2019 & Scavacini, K., Cornejo, E., \& Cescon, L. \\
\hline
\end{tabular}

Nota. Tabela elaborada pelas autoras

Tabela 3

Perda por suicídio na Família

\begin{tabular}{ccc}
\hline Título & Ano & Autor \\
\hline $\begin{array}{c}\text { Vivenciando o suicídio na família: do luto à } \\
\text { busca pela superação. }\end{array}$ & 2018 & Dutra, K. et al. \\
\hline $\begin{array}{c}\text { Suicídio: peculiaridades do luto das famílias } \\
\text { sobreviventes e a atuação do psicólogo }\end{array}$ & 2019 & Rocha, P. G., \& Lima, D. M. A. \\
\hline $\begin{array}{c}\text { Especificidades sobre o processo de luto } \\
\text { frente ao suicídio }\end{array}$ & 2016 & Fukumitsu, K. O. \& Kovács, M. J. \\
\hline
\end{tabular}

Nota. Tabela elaborada pelas autoras 


\section{Síntese Integradora}

Em relação ao tema do luto de pais sobreviventes por perda de filhos por suicídio e a atuação do psicólogo, os artigos encontrados especificam a subjetividade e a qualificação do profissional no acolhimento desses casos.

A partir de publicações, reportagens e entrevistas com pais afetados pelo suicídio de seus filhos, Feijoo (2021) salienta para a importância do profissional da psicologia em permanecer junto a dor e ao sofrimento desses pais. A partir da perspectiva fenomenológicoexistencial a autora explora a compreensão de morte, luto e clínica psicológica para enfatizar o papel do psicólogo frente a essa população. A partir das recomendações da Organização Mundial da saúde, a pesquisadora debate acerca das informações divulgadas sobre o suicídio de adolescentes e o sentimento de culpa dos pais. A divulgação de que os conflitos familiares estão atrelados ao suicídio, assim como a ideia de que o suicídio poderia ser evitado, é contramão à perspectiva fenomenológicaexistencial, a qual se isenta de uma moral no que se refere à responsabilização e culpabilização dos pais.

Os autores Serra e Freitas (2020) discutem acerca das especificidades do luto materno no suicídio, a partir de um estudo de caso. As autoras apontam que luto é um processo de transição e reorganização psicossocial com alto investimento emocional, frente a questões que provocam mudanças profundas em relação ao sentido da vida. Além disso, assinalam que a morte de alguém próximo por suicídio e o luto pela perda de um filho estão entre as principais circunstâncias que podem levar a um processo de luto considerado complicado. Sentimento de impotência, bem como o desamparo vivido na busca por um auxílio que se mostrava insuficiente são alguns sentidos encontrados nos relatos do caso. Além disso, as autoras discutem acerca dos desgastes das relações familiares frente ao antes e depois da morte do ente querido, bem como da experiência de suporte encontrado na família ampliada.
Feijoo (2021) afirma que o luto oriundo de morte por suicídio apresenta características muito peculiares. Os familiares referem-se à culpa, a vergonha e a revolta frente ao ato suicida de um dos membros da família. O autor enfatiza que nos atendimentos psicológicos dirigidos a sobreviventes, ele identificou que estes insistem em perguntar o que fizeram de errado, o porquê de não terem visto os avisos, como deveriam ter procedido etc. Alguns se referem também à vergonha e à dificuldade de retomarem suas tarefas laborais. O mesmo autor ainda relata sobre sua experiência com pais enlutados por suicidio, relatando que estes desejam fazer o mesmo que o filho e referemse ao fato de que a vida perdeu o sentido. Acabam por se sentirem culpados, ressentidos, solitários e fracassados. Torna-se evidente o risco de contágio, ou seja, quando um familiar comete o suicídio, mobiliza o outro a desejar fazer o mesmo.

Corroborando as ideias supracitadas, os autores Serra e Freitas (2020) enfatizam que o luto pela perda de um filho por suicídio é uma experiência de forte sentimento de culpa e cobranças - internas ou externas - sobre "erros" cometidos em sua educação. O luto descrito na literatura como uma experiência que jamais tem fim, pode prolongar-se por toda a vida pois, enquanto a pessoa que perde a mãe ou o pai torna-se órfã, a pessoa que perde um filho continua sendo mãe ou pai, porém de um filho que foi retirado de seus cuidados. Os autores reiteram a ideia de Feijoo (2021) acerca do sentimento de fracasso e erro dos pais diante dos filhos, questionando-se onde foi que erraram e buscando razões para compreender a atitude dos filhos em tirar a vida.

Por ser considerado uma morte socialmente carregada de estigmas e entendida como violenta, os sobreviventes enfrentam dificuldades ao tentar compreender o ato de seu ente querido. É um processo que pode levar ao afastamento das pessoas ao redor e ao isolamento, com consequentes sentimentos frequentemente ambivalentes (Serra \& Freitas, 2020). Devido essa mudança que toda a família precisa passar após perder um ente querido por suicídio, os pesquisadores sinalizam que não é 
por acaso que os enlutados por suicídio passam a ser chamados de sobreviventes, já que o impacto de ser sobrevivente é muito significativo para a saúde mental e se constitui em um dos principais indicadores de risco de suicídio.

Frente aos sentimentos dos pais e a atuação do psicólogo, Feijoo (2021) nos convida a refletir para além do suicídio, aliada à compreensão da dor da finitude a partir da compreensão da morte. A autora debate sobre o significado da existência e da esperança daquilo que está por vir, referindo-se a aspectos fundamentais da escuta do psicólogo frente aos pais enlutados por suicídio.

Em relação à posvenção, os autores ressaltam que a denominação é controversa, sendo que o termo é também identificado como pós-intervenção, tornando-se um termo confuso e não claramente delimitado. No Brasil, nos planos nacionais de intervenção, o termo nem sempre é utilizado em comum acordo, como acontece em outros países (Ruckert, Frizzo \& Rigoli, 2019).

Associado ao termo posvenção encontra-se o termo sobreviventes, para denominar os enlutados por suicídio. Porém, conforme apontam Ruckert, Frizzo e Rigoli (2019), esse conceito é também utilizado para aqueles que tentaram o suicídio e não resultaram em morte. Considerado como um grave problema de saúde pública, o suicídio é compreendido como um fenômeno multifatorial e de difícil abordagem social, já que ainda existe um estigma dos sujeitos e familiares envolvidos. De acordo com Scavacini (2018), preconceitos e tabus sobre o tema podem estar associados a fraqueza, coragem ou falta de religião, fatores esses que podem impedir as pessoas de buscarem ajudarem ao vivenciarem o luto por suicidío. Os autores Ruckert et al. (2019) ressaltam que o suicídio é o resultado de uma complexa interação de fatores psicológicos e biológicos, inclusive genéticos, culturais e socioambientais, não podendo ser atribuído a uma única causa ou campo de estudo.
Além do conceito de posvenção utilizados nos artigos encontrados nessa primeira temática, os autores Serra e Freitas (2020) enfatizam a importância da religiosidade como um outro recurso a utilizado para o enfrentamento da perda. A partir dos dados de pesquisa realizada pela Associação Brasileira de Estudos e Prevenção ao Suicídio (ABEPS) bem como pesquisadores do luto, os pesquisadores afirmam que a religiosidade e o suporte da rede de apoio entre os principais fatores de proteção ao enlutado, assim como poderosos recursos de enfrentamento da perda.

Para adentrar no tema das estratégias de prevenção e posvenção ao suicídio discorremos sobre os artigos que exploram com maior detalhamento essas práticas. Esses foram os principais temas das pesquisas de Müller, Pereira e Zanon (2017). A partir de entrevistas com cinco profissionais que atendem num Centro de Atenção Psicossocial (CAPS), as pesquisadoras apontam a importância do atendimento em rede e equipe, do atendimento humanizado às famílias e da importância da qualificação no manejo do suicídio. Dessa forma, a inclusão do usuário na rede, assim como o atendimento às famílias em caráter de prevenção, são ações destacadas como importantes para a realização daquilo que se denomina posvenção, ou seja, ações voltadas para a informação e escuta do sofrimento dos familiares e do usuário suicida ou com ideação suicida. O compartilhamento de ideias entre os profissionais do serviço, é apontado como uma ação positiva.

A partir de suas pesquisas, Müller et al. (2017) elaboraram um modelo de planejamento técnico referente à prevenção e posvenção ao suicídio para profissionais da saúde, diferenciando suas ações e intervenções junto à rede. $\mathrm{Na}$ prevenção os autores sugerem: inclusão do usuário e da família na rede (CAPS), atuação interdisciplinar da equipe qualificada, atenção às características e especificidades regionais, acolhimento humanizado. Em relação às ações voltadas para a posvenção, os pesquisadores incluem o apoio e acolhimento às famílias, através de grupo de apoio e escuta. Na posvenção, o atendimento e 
o olhar da rede estão direcionados para o usuário e sua família, enquanto na prevenção, a rede e a família aliam-se para a proteção do sujeito.

A posvenção pode ser uma atividade realizada em grupo. É uma experiência positiva que pode ser aprofundada nas pesquisas de Scavacini, Cornejo e Cescon (2019). Os pesquisadores apresentam um relato de experiência de posvenção do suicídio com o Grupo de Apoio aos enlutados por suicídio, abordando a importância desse espaço para a promoção de um suporte social que habitualmente é frágil ou inexistente no processo de luto dos sobreviventes por suicídio. A partir da experiência descrita com o grupo, enfatizam os procedimentos utilizados para a realização dos grupos e inserção dos participantes, além de algumas dicas de comportamentos esperados como respeito ao outro, oferta de suporte, compaixão e coragem ao outro, dentre outros. Os pesquisadores apontam para a escassez de material para os facilitadores do grupo, assim como de suporte social para os enlutados. Consideram que o grupo é um espaço que permite o enlutar-se, a partir da verbalização do pesar e sofrimento e afirmam o luto pelo suicídio como um não franqueamento social, ou seja, é um luto representando um sofrimento insuportável e um questionamento torturante e infindável para os que ficam.

Os autores Ruckert et al. (2019) realizaram uma revisão narrativa sobre os materiais existentes sobre posvenção do suicídio. Salientam que há uma escassez de material de literatura que descreva o impacto do suicídio e protocolos com estratégias de posvenção. No entanto, reforçam que a posvenção é uma estratégia de prevenção à medida que objetiva auxiliar no processo de luto e a desencorajar o planejamento de suicídio nos sobreviventes. Assim como Müller et al. (2017), os pesquisadores apontam que as estratégias de escuta, acolhimento e informação são importantes para uma melhor aceitação do evento traumático.

A vulnerabilidade emocional dos profissionais que trabalham com os casos de suicídio é comum. Por isso, os autores Müller et al. (2017) enfatizam a importância de estratégia que visem a saúde do trabalhador. O acompanhamento psicológico é uma das ações indicadas pelos pesquisadores. Concluem ainda que há uma escassez de programas governamentais de qualificação para os profissionais da saúde em relação a atuação e manejo de casos de suicídio. Ruckert et al. (2019) corroboram esses achados, enfatizando que os materiais encontrados sobre posvenção e luto por suicídio são voltados para orientações e informações referentes ao luto e focado em familiares, não em profissionais. Nesse sentido, Ruckert et al. (2019) sugerem mais pesquisas em relação às atividades interventivas da posvenção. Uma vez que aumenta significativamente as taxas de suicídio, aumenta também o risco de sobreviventes virem a adoecer, fazendo-se necessário realizar novas pesquisas para mapear orientações de posvenção. Dessa forma, os autores sugerem o desenvolvimento de pesquisas com o intuito de auxiliar no enfrentamento das situações e dos impactos decorrentes dessa vivência.

Em relação ao luto por suicídio na família, os autores contemplados nessa revisão ressaltam acerca do significado atribuído ao suicídio, bem como dos tabus e preconceitos envoltos. A compreensão de vivência das famílias frente a perda de um familiar por suicídio é possibilitada por pesquisas que explorem os sentimentos e o sofrimento dos participantes de pesquisa. Dutra et al. (2018) realizaram entrevistas com 20 participantes, entre profissionais da saúde e familiares de pessoas que cometeram suicídio, com o objetivo de compreender essa experiência. Dentre os principais resultados encontrados pelos pesquisadores, encontram-se os seguintes temas de discussão: o estado de choque, a convivência com o sofrimento $\mathrm{e}$ as repercussões da perda familiar e, a reconstrução da vida. Em relação ao estado de choque, os pesquisadores relatam que os participantes descrevem o suicídio como um ato de surpresa, ainda que o familiar apresentasse ideações suicidas. Em razão disso, pode ser comum 
buscar uma justificativa para a morte, como um assassinato e não suicídio. Diante da categoria de discussão sobre a convivência com o sofrimento e as repercussões da perda familiar, os pesquisadores ressaltam que o encontro dos familiares com o corpo do suicida torna-se um evento inesquecível. Da mesma forma, apontam que é tarefa árdua lidar com os julgamentos e cobranças da sociedade. Dutra et al. (2018) enfatiza que além de enfrentar a dor pela morte de um filho, esses pais precisam lidar com as cobranças e julgamentos da sociedade, buscando respostas para o suicídio e a sociedade de alguma maneira necessita de explicações e faz julgamentos precipitados. Desse modo, ao mesmo tempo em que os familiares são julgados pela sociedade, sentemse culpados por não terem conseguido evitar a morte.

Rocha e Lima (2019) corroboram esses achados a partir de uma revisão integrativa, enfatizam sentimentos de vergonha, medo e culpa associados aos motivos sentidos frente ao suicídio. De acordo com os achados desses pesquisadores, algumas crenças que podem dificultar o processo de elaboração do luto é o fato de os familiares não poderem se despedir do falecido e sofrerem com a violência desse tipo de morte ou porque o falecido não pensou neles. Os pesquisadores afirmam ser necessário um rearranjo do sistema familiar, construindo uma nova identidade e um novo equilíbrio. Assim, a família toda precisa passar por um processo de ressignificação para estabelecer um novo equilíbrio a partir dessa perda marcante, já que a pessoa que morreu não voltará ao sistema familiar, fazendo com que ela sofra mudanças importantes.

Dutra et al. (2018) citam que o luto por suicídio não pode ser atribuído a uma única compreensão, assim como o suicídio não pode ser explicado de forma simplista. Se trata de um luto que abarca diversas dimensões e o modo de lidar e vivenciar esse luto dependerá principalmente do relacionamento que $\mathrm{o}$ sobrevivente tinha com quem tirou a vida. $\mathrm{O}$ processo de luto será influenciado pela forma da morte (repentina ou violenta), o vínculo com a pessoa perdida e os antecedentes históricos e características de personalidade e sociais.

Os pesquisadores Fukumitsu e Kovács (2016) a partir de uma pesquisa com nove filhos de pessoas que consumaram o suicídio, encontraram os seguintes sentimentos vivenciados: culpa, raiva, sensações de desamparo, abandono, rejeição, solidão e fragmentação daquilo que era conhecido. A partir da análise dos conteúdos verbalizados com base no método fenomenológico, as autoras apresentam as unidades de sentido pertinentes à experiência de como é ser filho ou filha de um pai ou mãe que se suicidou. Sobreviver ao suicídio de um dos pais revelouse como uma situação desafiadora, pela surpresa e impacto causado pela forma como a morte do familiar se revela. Os pesquisadores afirmam que por ser uma morte violenta, repentina e que pode provocar culpa e autoacusação é demandada muita energia psíquica para a elaboração do luto, chegandose em algumas obras denominar o enlutado como sobrevivente.

Dentre as repercussões comuns encontradas diante da perda familiar, Dutra et al. (2018) salientam os problemas financeiros e o aparecimento de transtornos psíquicos. Em relação à reconstrução da vida, os resultados das pesquisas de Dutra et al. (2018) enfatizam o apoio da família, vizinhos e amigos como facilitador do processo de luto, auxiliando na minimização do sofrimento. Ressaltam ainda, que a superação dos desafios que surgem com o suicídio dentro do contexto familiar é fundamental para a reconstrução de uma vida saudável, sendo que a ajuda de um profissional é primordial. Conforme as contribuições de Rocha e Lima (2019), o tabu e o preconceito acerca do suicídio na sociedade contribuem para que os familiares reprimam seus sentimentos e o sofrimento das suas perdas.

$$
\text { Rocha e Lima (2019) contribuem }
$$
teoricamente para o debate acerca da importância da ajuda profisssional na elaboração do luto e, da necessidade de mais investimentos em posvenção para a qualificação dos profissionais e acolhimento da aflição das 
famílias em processo de luto por suicídio.

\section{Considerações finais}

Por meio da literatura encontrada, ficou evidente a limitação de publicação sobre a temática, por se tratar de um tema ainda estigmatizado e considerado tabu. Não foi encontrado literatura que relacione a intervenção precoce e o trabalho de posvenção ou prevenção ao suicídio e saúde mental. Em relação a temática de posvenção com pais enlutados por suicídio, percebe-se uma literatura escassa.

Com a pesquisa também ficou evidente que o luto por suicídio é menos estudado do que o suicídio e a prevenção, predominando estudos sobre os fatores predisponentes. As pesquisas referidas nesse estudo indicam a necessidade de avanços no entendimento sobre como as famílias vivenciam a perda de um ente querido por suicídio, pensando em desenvolver intervenções pelos profissionais de saúde. Os pesquisadores apontam a necessidade de que profissionais sejam capacitados para lidarem com a temática, uma vez que muitos familiares não encontram esse suporte na rede de assistência profissional disponível, sentindo-se desamparados.

A limitação de pesquisas em relação aos sentimentos e vivências com os sobreviventes de suicídio na família, podem refletir o tabu e o preconceito da sociedade em abordar mais amplamente o tema. Pode-se inferir pelos achados pesquisados que o enlutado pelo suicídio acaba vivenciando um luto solitário, silenciando seus sentimentos e emoções, sendo considerado um luto não reconhecido, ou um luto não sancionado. Os autores referem acerca da subjetividade envolvida nesse tipo de luto e, nesse sentido, pesquisas com os sobreviventes tornam-se fundamentais para uma compreensão melhor do fenômeno.

$\mathrm{Na}$ literatura encontrada fica evidente a especificidade do luto dos pais, uma vez que é um fato que vai contra o ciclo vital, sendo um luto trágico, repentino, inesperado $\mathrm{e}$ significativo. Devido ao grande índice de jovens que cometem suicídio, muitos pais acabam por enlutar-se e são considerados sobreviventes, muitas vezes sem cuidados e acolhimento necessários. Esse acolhimento pode ser chamado de posvenção, servindo como um trabalho de intervenção precoce, prevenindo desde cedo que esses enlutados possam vir a ter complicações devido a esse luto. Por outro lado, a temática de intervenção precoce é pouco divulgada como uma implicação na posvenção, uma vez que além de acolher o sofrimento dos enlutados ela pode prevenir o sofrimento de gerações futuras e a recorrência de tentativas de suicídio nos sobreviventes.

Sugere-se, portanto, mais pesquisas na temática, que relacionem a posvenção com o conceito de intervenção precoce, pensando essa intervenção como uma prevenção e profilaxia aos enlutados que estão em um processo doloroso e significativo. Intervir precocemente, após a perda por suicídio, oferecendo espaço de cuidado, acolhimento e escuta, possibilitará que esses pais não desenvolvam um luto complicado, protegendo sua saúde mental, evitando assim outros suicídios. As mesmas pesquisas se fazem importantes, para o preparo de profissionais da saúde ao lidarem com os sobreviventes e promoverem espaços de cuidado, compartilhamento, psicoeducação e promoção de prevenção.

É urgente pensarmos em trabalhos de posvenção e intervenções precoces para com esses enlutados, pensando que estes correm um grande risco de desenvolverem um luto complicado, transtornos mentais ou até mesmo ideações suicidas, se não cuidados de forma adequada. Para tanto é importante o preparo de profissionais da saúde para lidar com a temática e pesquisas relevantes nessa área, onde possa ser relacionada a intervenção precoce e a posvenção, proporcionando trabalhos de prevenção a esses enlutados pela perda de filhos. Esses enlutados necessitam de um acolhimento adequado, através de espaços de cuidados a fim de elaborarem seus lutos de forma saudável.

Pensando ser um acontecimento que 
ocorre cada vez mais, pensa-se que pesquisas nessa área são importantes até mesmo para os profissionais de saúde, que também sentem o impacto dessa morte. Precisamos falar sobre suicídio de forma responsiva pensando em prevenção, mas precisamos estar cientes de que muitas pessoas acabam tirando suas vidas por multifatores, portanto também não podemos esquecer de falar sobre o cuidado com os enlutados pelo suicídio.

\section{Referências}

Associação Brasileira de Psiquiatria (2014).

Suicídio: informando para prevenir.

Conselho Regional de Medicina, Brasília.

Recuperado de

http://www.flip3d.com.br/web/pub/cfm/ind ex9/?numero $=14$.

Bromberg, M. H. P. F. (1998). A psicoterapia em situações de perdas e luto. São Paulo: Editora Psy

Botega, N. J. (2015). Crise suicida: avaliação e manejo. Porto Alegre: Artmed.

Casellato, G. (2015). O resgate da empatia:

Suporte Psicológico ao Luto não

Reconhecido. São Paulo: Summus editorial.

Casellato, G. (2002). Luto pela perda de um filho: a recuperação possível diante do pior tipo de perda. In M. H. P. Franco

(Org.), Uma jornada sobre o luto: a morte e o luto sob diferentes olhares (pp. 11-21). Campinas: Livro Pleno.

Dutra, K., Preis, L. C., Corrêa, L., Caetano J., Santos, J. L. G., Lessa, G. (2018).

Vivenciando o suicídio na família: do luto à busca pela superação. Revista Brasileira de Enfermagem, 71(5), 2146-2153. doi: 10.1590/0034-7167-2017-0679

Feijoo, A. M. L. C. (2021). Situação de Suicídio: Atuação do Psicólogo junto a pais enlutados. Psicologia Em Estudo, 26, e44427. doi: 10.4025/psicolestud.v26i0.44427.

Franco, M. H. P. (2010). Formação e rompimento de vínculos: o dilema das perdas na atualidade. São Paulo: Summus Editorial.

Fukumitsu, K. O., \& Kovács, M. J. (2015). O luto por suicídios: uma tarefa da posvenção. Revista Brasileira de Psicologia, 2(2), 4147. Recuperado de https://repositorio.usp.br/item/002799077

Fukumitsu, K. O. \& Kovács, M. J. (2016). Especificidades sobre processo de luto frente ao suicídio. Psico, 47(1), 03-12. doi: 10.15448/1980-8623.2016.1.19651

Kovács, M.J. (2003) Educação para a Morte. Temas e Reflexões São Paulo: Casa do Psicólogo.

Lima, T.C.S, Mioto, R.C.T. (2007).

Procedimentos metodológicos na construção do conhecimento científico: a pesquisa bibliográfica. Revista Katál, 10(n. esp.), 37-45. doi: $\underline{10.1590 / \text { S1414- }}$ 49802007000300004

Müller, S. A., Pereira, G. \& Zanon, R. B. (2017). Estratégias de prevenção e pósvenção do suicídio: Estudo com profissionais de um Centro de Atenção Psicossocial. Revista de Psicologia da IMED, Passo Fundo, 9(2), 6-23.

Recuperado de http://pepsic.bvsalud.org/scielo.php?script= sci arttext\&pid=S217550272017000200002

Parkes, C. M. (2009). Amor e Perda: as raízes do luto e suas complicações. São Paulo: Summus Editorial.

Rocha, P. G., \& Lima, D. M. A. (2019). Suicídio: peculiaridades do luto das famílias sobreviventes e a atuação do psicólogo. Psicologia Clínica, 31(2), 323344. doi: 10.33208/PC19805438V0031N02A06.

Ruckert, M. L. T; Frizzo, F. P. \& Rigoli, M. M. (2019). Suicídio: a importância de novos estudos de posvenção no Brasil. Revista Brasileira de Terapias Cognitivas, 15(2), 85-91. Recuperado de http://pepsic.bvsalud.org/scielo.php?script= sci arttext\&pid=S180856872019000200002.

Salvador, A. D. (1986). Métodos e técnicas de pesquisa bibliográfica. Porto Alegre: Sulina. 
Scavacini, K. (2018). O suicídio é um problema de todos: a consciência, a competência e o diálogo na prevenção e posvenção do suicídio (Tese de Doutorado). Instituto de Psicologia, Universidade de São Paulo, SP, Brasil.

Scavacini, K., Cornejo, E., \& Cescon, L. (2019). Grupo de Apoio aos Enlutados pelo Suicídio: uma experiência de posvenção e suporte social. Revista M. Estudos sobre a morte, os mortos e o morrer, 4(7), 201-214. doi:10.9789/2525-3050.2019.v4i7.201-214

Serra, A. P. E. \& Freitas, J. L. (2020). Luto materno no suicidio: a impotência e o desamparo frente as (im)possibilidades. Rev. Nufen: Phenom. Interd. Belém, 12(3), 19-37. Recuperado de http://pepsic.bvsalud.org/scielo.php?script= sci arttext\&pid=S217525912020000300003

Shneidman, E. (1973). Deaths of a man. New York: Quadrangle.

Tavares, M. S. A. (2013). Capítulo IV. In Conselho Federal de Psicologia, O suicídio e os desafios para a psicologia (pp. 45-58). Brasília: CFP. Recuperado de https://site.cfp.org.br/publicacao/suicidio-eos-desafios-para-a-psicologia/

\section{Dados sobre as autoras:}

- Luana Dondé Tochetto: Especialista em Teoria Pesquisa e Intervenção em Luto e PerdasInstituto Quatro Estações, São Paulo: SP. Formação em Intervenção em Crises e EmergênciasInstituto Quatro Estações São Paulo, SP. Doula da morte- Instituto Amortser. Mestranda do PPGPSI no Mestrado Profissional em Psicologia da Universidade de Caxias do Sul/UCS.

- Raquel Furtado Conte: Doutora em Diversidade de Inclusão Social, Mestre em Psicologia da Universidade de Caxias do Sul/UCS- RS. Professora Adjunta do Curso de Graduação e PosGraduação em Psicologia e Mestrado Profissional em Psicologia/PPGPSI- Linha 1- Saúde e Processos Psíquicos da Universidade de Caxias do Sul/UCS- RS. poderão utilizar os mesmos resultados em outras publicações indicando claramente este periódico como o meio da publicação original. Em virtude de sermos um periódico de acesso aberto, permite-se o uso gratuito dos artigos em aplicações educacionais e científicas desde que citada a fonte conforme a licença CC-BY da Creative Commons. 